\title{
A novel knockout mouse for the small EDRK-rich factor 2 (Serf2) showing developmental and other deficits
}

\author{
Karen Cleverley ${ }^{1}$. Weaverly Colleen Lee ${ }^{1} \cdot$ Paige Mumford $^{1,2}$. Toby Collins ${ }^{1} \cdot$ Matthew Rickman ${ }^{1}$. \\ Thomas J. Cunningham ${ }^{3}$. James Cleak ${ }^{3}$. Joffrey Mianne ${ }^{4} \cdot$ Zsombor Szoke-Kovacs $^{4}$ - Michelle Stewart ${ }^{3}$. \\ Lydia Teboul $^{3}$. Cheryl Maduro ${ }^{1} \cdot$ Sara Wells $^{4}$ - Frances K. Wiseman ${ }^{1,2}$. Elizabeth M. C. Fisher ${ }^{1}$
}

Received: 12 December 2020 / Accepted: 22 February 2021 / Published online: 13 March 2021

(c) The Author(s) 2021

\begin{abstract}
The small EDRK-rich factor 2 (SERF2) is a highly conserved protein that modifies amyloid fibre assembly in vitro and promotes protein misfolding. However, the role of SERF2 in regulating age-related proteotoxicity remains largely unexplored due to a lack of in vivo models. Here, we report the generation of Serf2 knockout mice using an ES cell targeting approach, with Serf 2 knockout alleles being bred onto different defined genetic backgrounds. We highlight phenotyping data from heterozygous Serf $2^{+/-}$mice, including unexpected male-specific phenotypes in startle response and pre-pulse inhibition. We report embryonic lethality in $\operatorname{Serf}^{-/-}$null animals when bred onto a C57BL/6 N background. However, homozygous null animals were viable on a mixed genetic background and, remarkably, developed without obvious abnormalities. The Serf 2 knockout mice provide a powerful tool to further investigate the role of SERF2 protein in previously unexplored pathophysiological pathways in the context of a whole organism.
\end{abstract}

\section{Introduction}

The molecular events that occur in cells during ageing can inform our understanding of age-related diseases. Many neurodegenerative diseases share the hallmark appearance of fibrillar protein aggregates in the brain, and while the role of these aggregates in disease remains unclear, such fibrillary structures are composed of aggregation-prone proteins, for example, mutant huntingtin (HTT) in Huntington disease, $\alpha$-synuclein in Parkinson disease and amyloid-beta $(\mathrm{A} \beta)$ in Alzheimer disease (Scherzinger et al. 1999; Chiti and Dobson 2006; Goedert and Spillantini 2006). Although the contribution of aberrantly folded protein aggregates to the pathogenesis of disease is not fully understood, the current

Elizabeth M. C. Fisher

elizabeth.fisher@ucl.ac.uk

1 Department of Neuromuscular Diseases, Queen Square Institute of Neurology, London, UK

2 The UK Dementia Research Institute, University College London, Queen Square, London WC1N 3BG, UK

3 Mammalian Genetics Unit, Harwell, UK

4 Mary Lyon Centre, MRC Harwell Institute, Oxfordshire OX11 0RD, UK most prevalent hypothesis is that aggregation intermediates are toxic to cells and that the aggregation process is a cellular protection mechanism against these cytotoxic intermediates (Lansbury and Lashuel 2006; Hartl and Hayer-Hartl 2009; Ogen-Shtern, Ben David, and Lederkremer 2016).

SERF proteins are evolutionarily conserved and positively regulate protein aggregate formation (van Ham et al. 2010; Falsone et al. 2012; Meinen et al. 2019; Merle et al. 2019; Meyer et al. 2020). Genetic screens for modifiers of aggregation in Caenorhabditis elegans models led to the identification of Modifier of Aggregation 4 (MOAG-4) (van Ham et al. 2010) and Cytotoxicity-Related Aggregation Mediator-1 (CRAM-1) (Balasubramaniam et al. 2018), the human orthologs of which are SERF1A and SERF2 respectively. These proteins are thought to regulate age-related proteotoxicity through a previously unexplored pathway (Stroo et al. 2017). Inactivation of MOAG-4 suppresses protein aggregation and associated toxicity in $C$. elegans models (van Ham et al. 2010) and SERF1A accelerates the aggregation of amyloidogenic proteins in vitro (Falsone et al. 2012). MOAG-4 also promotes the aggregation of $\alpha$-synuclein by interfering with intramolecular interactions (Yoshimura et al. 2017). CRAM-1 blocks proteasomal degradation of ubiquitinated proteins and thus promotes aggregation (Ayyadevara et al. 2015) and SERF2 promotes aggregation of $A \beta$ 
in human neuroblastoma cells overexpressing APP (amyloid precursor protein) (Balasubramaniam et al. 2018).

Native mass spectrometry shows that SERF proteins exhibit a high degree of plasticity and can form fuzzy, highly extended complexes with amyloid-prone proteins such as A $\beta 40$ and $\alpha$-synuclein (Meinen et al. 2019); this protein-protein interaction is biologically active but disordered, yet is sufficient to potentiate cytotoxic aggregation (Merle et al. 2019). The disordered nature of SERF proteins allows conformational adaptation; SERF1A has been shown to bind RNA, accumulating in the nucleus under physiological conditions; however, under stress conditions SERF1A is rapidly released into the cytosol where it favours binding to $\alpha$-synuclein (Meyer et al. 2020). This suggests a physiological role and, in stress, a pathological gain-of-interaction for SERF1A. The function of its paralogue, SERF2 also a largely disordered protein, remains to be determined (Balasubramaniam et al. 2018).

Here we describe Serf 2 knockout mice that will provide a platform for the exploration of the role of SERF2 in the aggregation of proteins involved in the pathology of neurodegenerative diseases. Our characterisation includes finding a tissue-specific pattern of expression, a role in development that is essential on one genetic background, and a malespecific phenotype affecting startle response and pre-pulse inhibition in heterozygous knockout animals.

\section{Materials and methods}

\section{Animal welfare and husbandry}

All animals were housed and maintained in the Mary Lyon Centre, MRC Harwell Institute and at UCL, under specific pathogen-free (SPF) conditions, in individually ventilated cages adhering to environmental conditions as outlined in the Home Office Code of Practice. All animal studies were lisensed by the Home Office under the Animals (Scientific Procedures) Act 1986 Amendment Regulations 2012 (SI 4 2012/3039), UK, and additionally approved by the Institutional Ethical Review Committees. All mice were co-housed throughout the study as lone housing is known to modify phenotypes; mice were housed with littermates and/or animals of the same sex weaned at the same time, thus mice of differing genotypes were co-housed pseudorandomly. Mice had access to a mouse house with bedding material and wood chips. All animals had continual access to water and RM1 (Special Diet Services) (stock animals) or RM3 (Special Diet Services) (breeding animals) chow. Animals were euthanized following Schedule 1 methods in accordance with the Animals (Scientific Procedures) Act 1986 (United Kingdom).

\section{Generation of Serf2 knockout C57BL/6 mice}

Serf2 conditional ready ES cells and mice (allele name: Serf2 $2^{\text {tmla(EUCOMM)Hmgu) }}$, MGI:5,771,993) were generated in collaboration with the International Mouse Knockout Consortium (https://www.mousephenotype.org/), via a mouse embryonic stem (ES) cell targeting approach using C57BL/6Ntac ES cells, such that exon 2, a critical exon, was flanked by loxP sites (Serf2 has three exons) (Fig. 1).

Subsequently the Mary Lyon Centre at MRC Harwell used recombination at $\operatorname{lox} P$ sites via soluble Cre protein (TAT-Cre (Tat-NLS-Cre, HTNC, HTNCre), Excellagen, Rockville, USA) during in vitro fertilisation, to remove critical exon 2 and generate the null $\operatorname{Serf} 2^{\text {tmlb }}$ allele (MGI: 6,120,704) that expresses a $\beta$-gal reporter under the endogenous promotor. An additional IVF was carried out using $\operatorname{Serf} 2^{\text {tmla }}$ sperm with oocytes from a Flp recombinase

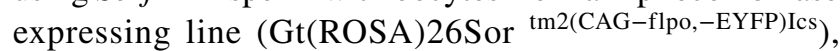
after fertilisation, embryos at a two-cell stage were exposed to soluble Cre as above, to create the null Serf $2^{\text {tmld }}$ allele (MGI: 6,317,359) as shown (Fig. 1).

\section{Animal cohorts}

Cohort A: (E14.5 for microCT) WT $n=8, \operatorname{Serf}^{+/-} n=11$, Serf $2^{-/-} n=6$; tm1b allele, co-isogenic on C57BL/6NTac.

Cohort B: (3-month-old males for protein and qPCR) WT $n=4, \operatorname{Serf}^{+/-} n=4, \operatorname{Serf}^{-/-} n=3$; tm1d allele, mixed background (produced by the Serf $2^{\text {tmld }}$ allele in multigeneration inter-crosses of 128S8, C57BL/6Nimr and C57BL/6 J).

Cohort C: (3-month-old males and females for behavioural profiling) WT $n=2,172, \operatorname{Serf}^{+/-} n=15 ; \mathrm{tm} 1 \mathrm{~b}$ allele, co-isogenic on C57BL/6NTac. We note that wildtype animals are the baseline control mice from the International Mouse Phenotyping Consortium pipeline, hence the large number of controls; please see text below.

In addition, 15-week-old males and females of this genotype (tm1b allele)/genetic background (C57BL/6NTac), wildtype and heterozygous littermates, were used for gene expression analysis by $\mathrm{X}$-gal staining.

\section{DNA extraction and genotyping}

DNA was extracted from tail tip or ear biopsy by the Hot Shot method (Truett et al. 2000). Mice were genotyped using polymerase chain reaction (PCR) for the presence of Serf2 (control primers f: 5'- CTC CGG CGT CTC ACT TTG TAC CT -3' r: 5'- CAC TCT GCC CCT CAC ATC TAA CC-3', Serf2 knockout specific primers f: 5'- AAG GCG CAT AAC GAT ACC AC - 3' r: 5'- ACT GAT GGC GAG CTC AGA CC $-3^{\prime}$ ); giving a 274 bp product for the wildtype (WT) allele and a $174 \mathrm{bp}$ product for the targeted allele. 
(A)

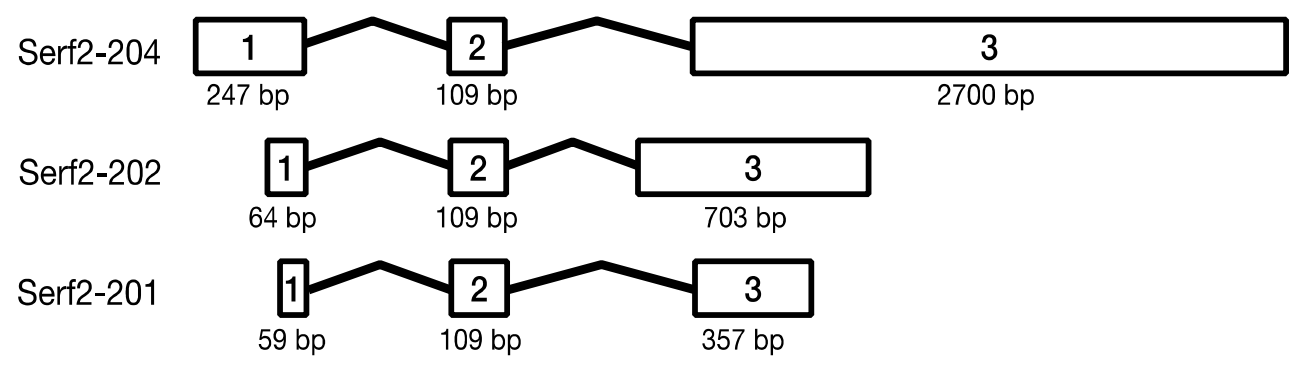

(B)

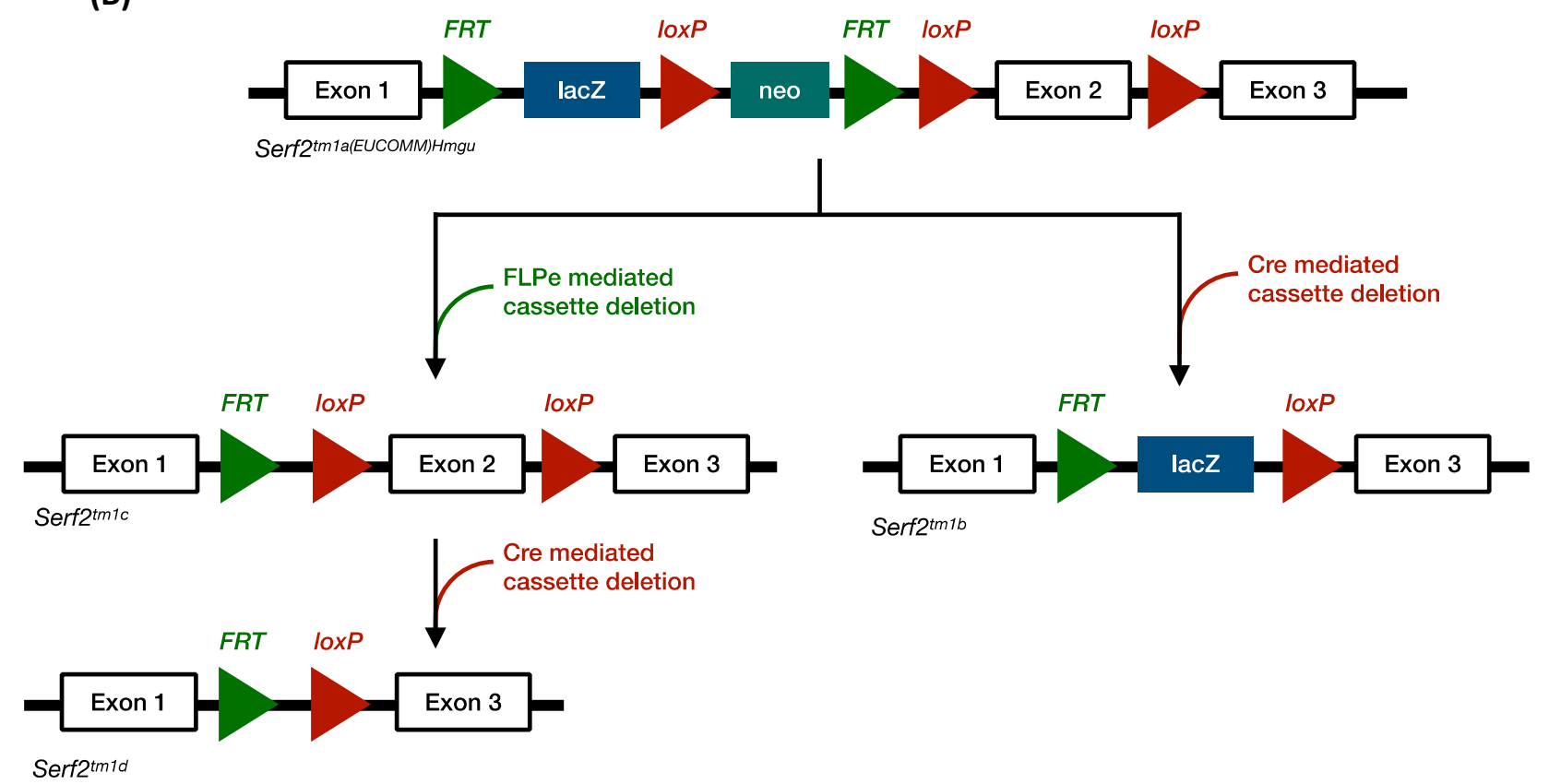

(C)

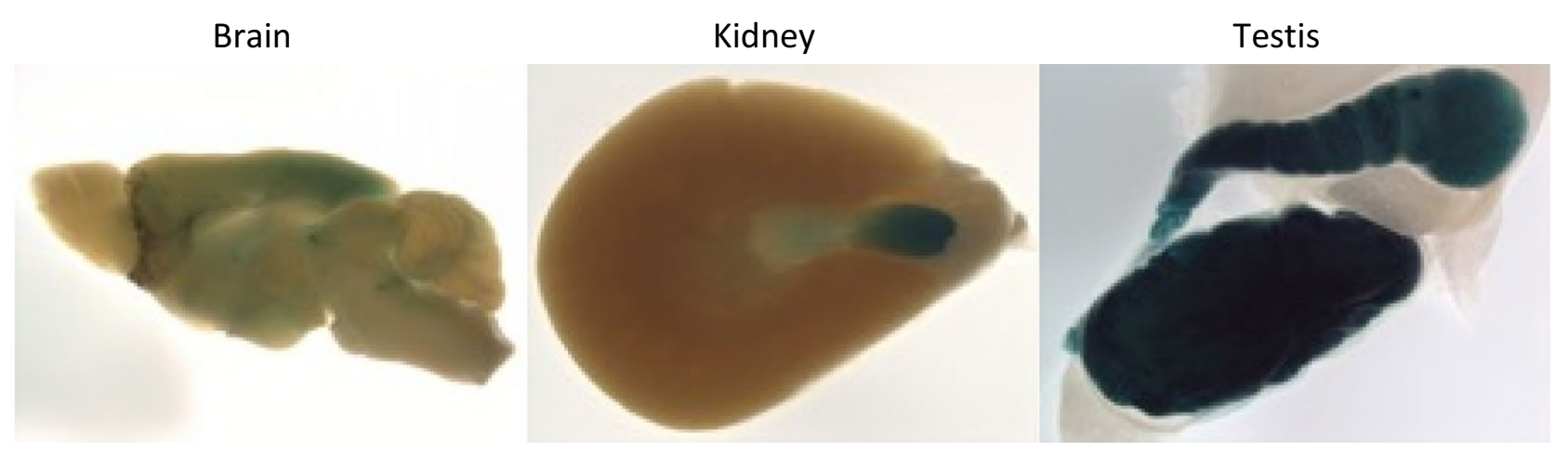

Fig. $1 \operatorname{Serf}^{\text {tmlb }}$ allele and gene expression. a Schematic of Serf2 locus showing alternatively spliced protein coding transcripts published in the mouse Ensembl genome database (Mouse reference assembly GRCm38.p6). b International Mouse Knockout Project strategy to create the $\operatorname{Serf} 2^{\text {tmIlb}}$ and $\operatorname{Serf} 2^{\text {tmIld }}$ alleles. Note:
Serf $2^{\text {tmla }}$ MGI: 5,771,993; $\operatorname{Serf} 2^{\text {tmlb }}$ MGI: 6,120,704; $\operatorname{Serf} 2^{\text {tmld }}$ MGI: 6,317,359. c Examples of X-gal staining in 15-week-old heterozygous adults (C57BL/6 N background). Shown from left to right: sagittal brain section, kidney and testis. All organs were a similar size to those of wildtype controls at this age 
The PCR buffer was: $1 \times$ MegaMix Blue Buffer (supplied as $10 \times$ stock, Microzone) and $1 \mu \mathrm{M}$ of each genotyping primer, PCR conditions were as follows: $95^{\circ} \mathrm{C}$ for $1 \mathrm{~min}, 30$ cycles at $95{ }^{\circ} \mathrm{C}$ for $10 \mathrm{~s}, 60{ }^{\circ} \mathrm{C}$ for $10 \mathrm{~s}, 72^{\circ} \mathrm{C}$ for $1 \mathrm{~s}$, and 1 cycle of $72{ }^{\circ} \mathrm{C}$ for $30 \mathrm{~s}$. PCR products were resolved by electrophoresis on 2\% agarose gels in TBE (Tris-Borate-EDTA) with $1 \mu \mathrm{g} / \mathrm{ml} \mathrm{GelRed}{ }^{\circledR}($ Biotium), run at $100 \mathrm{~V}$ and constant current.

\section{RNA extraction and quantitative RT-PCR}

Total cortical RNA was extracted using the RNeasy ${ }^{\circledR}$ mini kit (Qiagen). Tissue (Cohort B animals) was disrupted using a TissueRuptor ${ }^{\circledR}$ (Qiagen), and the protocol followed as per the manufacturer's instructions, samples were defrosted and homogenised on ice. Final extracted RNA was eluted in DNase- and RNase-free water. Amounts of RNA were equalised and cDNA was generated using the SuperScript ${ }^{\text {TM }}$ First-Strand Synthesis System for RT-PCR (Invitrogen). Quantitative PCR was undertaken to determine expression of all isoforms of Serf2 (primers f: 5'-ATG ACC CGC GGT AAC CAG-3' r: 5'-GAA GAA GCA GAG CGA CTC GG-3' probe FAM-CGA GAG CTC GCC CGC CAG AAG AAC A). Mouse $\beta$-actin (Actb) control mix (4354315 Applied Biosystems) was used as an endogenous control with a VIC ${ }^{\circledR}$ dye-labelled TaqMan ${ }^{\circledR}$ MGB probe. Minus reverse-transcriptase controls were run for every sample for all reactions. No evidence of genomic amplification was detected (Wiseman et al. 2018).

\section{Tissue preparation and western blotting}

For analysis of protein abundance in the cortex, tissue (Cohort B animals) was dissected under ice-cold PBS before snap freezing. Samples were then homogenised in RIPA Buffer ( $150 \mathrm{mM}$ sodium chloride, $50 \mathrm{mM}$ Tris, $1 \%$ NP- $40,0.5 \%$ sodium deoxycholate, $0.1 \%$ sodium dodecyl sulphate) plus complete protease inhibitors (Calbiochem) by mechanical disruption. Total protein content was determined by Bradford assay. Samples from individual animals were run separately and were not pooled. Equal amounts of total brain proteins were then denatured in LDS denaturing buffer (Invitrogen) and $\beta$-mercaptoethanol, prior to separation by SDS-PAGE gel electrophoresis using precast 4-12\% Bis-Tris gels (Invitrogen). Proteins were transferred to nitrocellulose membranes prior to blocking in 5\% milk/ PBST $(0.05 \%$ Tween-20). Primary antibodies were diluted in $1 \%$ BSA/PBST, HRP conjugated secondary anti-rabbit and anti-mouse antibodies (Dako) were diluted 1:5000 in 1\% BSA/PBST. Primary antibodies against SERF2 (Proteintech 11691-1-AP, 1:1000) and $\beta$-actin (Sigma A5441, 1:60,000) were used.

\section{Gene expression analysis in adult mice}

For analysis of gene expression by X-gal staining (Cohort C) the following protocol was undertaken. Day $1-$ All solutions at $\mathrm{pH}$ 8.0. Adult, anaesthetised mice between 8-16 weeks of age were perfused using $40 \mathrm{ml} 4 \%$ PFA in PBS over $15 \mathrm{~min}$. A standard set of tissues were extracted (Supplementary Table S1) and placed into $200 \mathrm{ml}$ 4\% PFA to fix for a further 30 min on ice. The brain was cut sagittally using a brain matrix into $\sim 1 \mathrm{~mm}$ sections that were placed into a histological cassette. All tissues were then subject to $3 \times 20 \mathrm{~min}$ washes in $200 \mathrm{ml} 1 \times \mathrm{PBS}$ at $4{ }^{\circ} \mathrm{C}$. Tissues were then incubated in $200 \mathrm{ml} \mathrm{LacZ}$ solution $\left(2 \mathrm{mM} \mathrm{MgCl} \cdot \mathrm{H}_{2} 0,0.02 \%\right.$ IGEPAL, $5 \mathrm{mM}$ potassium ferrocyanide, $5 \mathrm{mM}$ potassium ferricyanide, $10 \%$ sodium deoxycholate, $1 \mathrm{mg} / \mathrm{ml} \mathrm{X-gal} \mathrm{in}$ dimethylformamide made up in $1 \times$ PBS and filtered using a $0.2 \mu \mathrm{M}$ steritop filter) for $48 \mathrm{~h}$ at $4{ }^{\circ} \mathrm{C}$. Day 3 -Tissues were washed $2 \times 30 \mathrm{~min} 1 \times$ PBS followed by an overnight post-fix in 4\% PFA. Day 4-Tissues were rinsed with $1 \times$ PBS and kept overnight in 50\% glycerol (in PBS). Day 5-The glycerol was replaced with 70\% glycerol (in PBS) and samples were kept in the dark at $4{ }^{\circ} \mathrm{C}$ until imaging. Imaging was carried out on a Leica M165C stereo microscope using a Jenoptik ProgRes speed $\mathrm{XT}^{\text {core }} 5$ camera and images stored in an iMagic IMS client as a JPEG.

\section{Sample preparation for MicroCT}

Mice were mated and detection of a vaginal plug the following morning was considered to be $0.5 \mathrm{dpc}$. At $14.5 \mathrm{dpc}$ pregnant females were sacrificed by cervical dislocation and the uterine horns dissected out. Individual embryos (Cohort A animals) were removed from placentae and allowed to bleed out in cold PBS for $\sim 10$ min. During this period any scab that had formed over the umbilical area was removed to allow for continued bleeding. Embryos were placed in individual wells of a Corning Costar 6-well plate and fixed in $10 \mathrm{ml}$ of $4 \%$ PFA, pH 8 on a rocker at $4{ }^{\circ} \mathrm{C}$ overnight. Once fixation was confirmed embryos were stored in $1 \%$ PFA, pH 8 until ready for potassium tri-iodide (Lugol) staining. Embryos were placed in individual glass bijou bottles with $15 \mathrm{ml}$ of contrast agent, 50\% Lugol solution (32922, Sigma-Aldrich) made up in distilled water $\left(\mathrm{dH}_{2} \mathrm{O}\right)$. These were wrapped in foil to protect from light and placed on a rocker at room temperature for two days. Following contrast samples were rinsed and then washed with $\mathrm{dH}_{2} \mathrm{O}$ for at least one hour to remove any excess contrast solution. Samples were then embedded in $1 \%$ Iberose high specification agarose (AGR-500, Web Scientific) in $4.5 \mathrm{ml}$ CryoTube vials. Samples were left to set in the agarose for a minimum of two hours at room temperature prior to scan initiation. 


\section{MicroCT imaging}

For each embryo 3D datasets were acquired using a Skyscan 1172 high resolution microCT scanner (Bruker). Scans were carried out with the X-ray source at $80 \mathrm{kVp}$ and $124 \mu \mathrm{A}$ and using an aluminium filter. Using the NRecon software supplied with the microCT scanner slices were reconstructed into digital cross-sections by a Feldkamp algorithm for cone beam CT (Feldkamp et al. 1984). The resulting 3D dataset is $4000 \times 4000 \times 2000$ voxels of $2.96 \mu \mathrm{m}$.

\section{MicroCT post-processing}

Following reconstruction $3 \mathrm{D}$ datasets underwent further processing through an in-house programme, HARP (Brown et al. 2018), which automatically crops tightly around the sample to remove empty data. It also allows for the dataset to be resampled to more manageable sizes. Samples were routinely cropped and resized to a voxel size of $14 \mu \mathrm{m}$ using HARP. Once post-processed datasets were viewed in 3D Slicer (http://slicer.org/) or FIJI (http://fiji.sc/wiki/index .php/Fiji).

\section{Acoustic startle and pre-pulse inhibition}

Mice from Cohort $\mathrm{C}$ were placed in an acoustic startle chamber (Med Associates Inc, USA) and acclimatised to a background noise level of $53 \mathrm{~dB}$ for $5 \mathrm{~min}$, followed by exposure to $5120 \mathrm{~dB}$ startle tones. Mice were then exposed to a startle tone at $120 \mathrm{~dB}$ for $40 \mathrm{~ms}$, either on its own or preceded $80 \mathrm{~ms}$ earlier by a $20 \mathrm{~ms}$ pre-pulse at 56,58 or $65 \mathrm{~dB}$ (PPI, PPI2, PPI3). Responses to the startle tone were measured for $100 \mathrm{~ms}$ following the start of the startle tone using a piezoelectric transducer in the floor of the chamber which detected movement of the animal. Each trial condition was tested 10 times. More details available at IMPRESS (www. mousephenotype.org/impress).

\section{Results}

\section{Generation of Serf2 knockout mice, gene expression pattern in adults, and homozygous early embryonic lethality on a C57BL/6 $\mathrm{N}$ background}

Serf2 knockout mice were generated in collaboration with the International Mouse Knockout Project using a mouse embryonic stem (ES) cell targeting approach. The knockout allele, $\operatorname{Serf} 2^{\text {tmlb }}$ has exon 2 deleted from this three-exon gene (Fig. 1a), and instead expresses a LacZ sequence that is driven by the endogenous promotor and so, after beta-galactosidase staining, indicates spatial and temporal expression of $\operatorname{Serf2}$ (Fig. 1b) (Skarnes et al. 2011) (Murray 2020).

SERF2 expression in adults (15 weeks of age) was assessed using beta-galactosidase staining from the $\operatorname{Serf} 2^{t m 1 b}$ allele in heterozygous mice on the congenic on C57BL/6Ntac background. Expression was clearly seen in discrete regions within heart, blood vessels, throughout the brain and spinal cord, adrenal gland, kidney, male and female gonads, and uterus (for examples, see Fig. 1c). Unexpectedly, male-only expression was seen in the trachea, thyroid and parathyroid. No LacZ staining could be detected in the gut, brown or white adipose, pancreas, thymus, spleen, cartilage, bone, skeletal muscle, lung, mammary gland or peripheral nervous system; see Supplementary Table S1 for full list of tissues assessed and more expression data are available at www.mousephenotype.org.

In this programme, embryonic lethality is defined by the collection of 28 embryos and none having the genotype of interest, at a particular timepoint. When pups were assessed from a heterozygous intercross, by this definition complete knockout of the Serf2 gene (homozygous $\operatorname{Serf} 2^{\text {tmlb }}$ allele) was lethal when mice were maintained on the C57BL/6Ntac background: when E18.5 embryos were sampled, genotype percentages were similar for wildtype, heterozygous and homozygous embryos (Fig. 2a). However, at birth, although we were able to genotype 5 homozygous P1 pups out of 110 total neonates, all 5 died within P1. This indicates substantial loss of homozygotes between E18.5 and P1.

Furthermore, from this intercross we found 42 wildtype mice at $\mathrm{P} 1$, and so would expect $\sim 84$ heterozygotes, whereas we found only 63 heterozygotes, showing loss of fitness for this genotype at this stage. We note we found no homozygous animals at weaning (Fig. 2a).

MicroCT analysis of six Serf2 null compared to six wildtype littermate E14.5 embryos showed widespread developmental defects and reduced embryo size (embryo volume) (Fig. 2b). Defects include abnormal entry point/ angle of the ductus into the heart in 3/6 animals, oedema (4/6), pulmonary trunk deficits $(3 / 6)$, lung deficits $(5 / 6)$ interventricular septal defects (4/6) and abnormal rib fusion (6/6). These data show incomplete penetrance and variable expressivity of dysmorphology defects of the Serf2 null phenotype on the inbred C57BL/6Ntac background, in keeping with previous observations of other knockout animals on this background (Dickinson et al. 2016). Some of these deficits - the interventricular septal defect, lung lobe deficit and abnormal rib fusion, appear to resolve and are not present by E18.5 indicating developmental delay in the embryos (data available but not shown). 
(A)

\begin{tabular}{|c|c|c|c|c|c|c|c|}
\hline Stage & $\begin{array}{c}\text { Litters } \\
\text { collected }\end{array}$ & $\begin{array}{c}\text { Embryos/P1 } \\
\text { collected }\end{array}$ & Resorption & Wildtype & Heterozygous & Homozygous & Unknown \\
\hline E12.5 & 5 & 40 & 5 & 12 & 15 & 12 & 1 \\
\hline E14.5 & 3 & 25 & 3 & 8 & 11 & 6 & 0 \\
\hline E18.5 & 4 & 33 & 6 & 5 & 18 & 7 & 3 \\
\hline P1 & 7 & 110 & & 42 & 63 & $5 *$ & \\
\hline
\end{tabular}

*died within P1

(B)
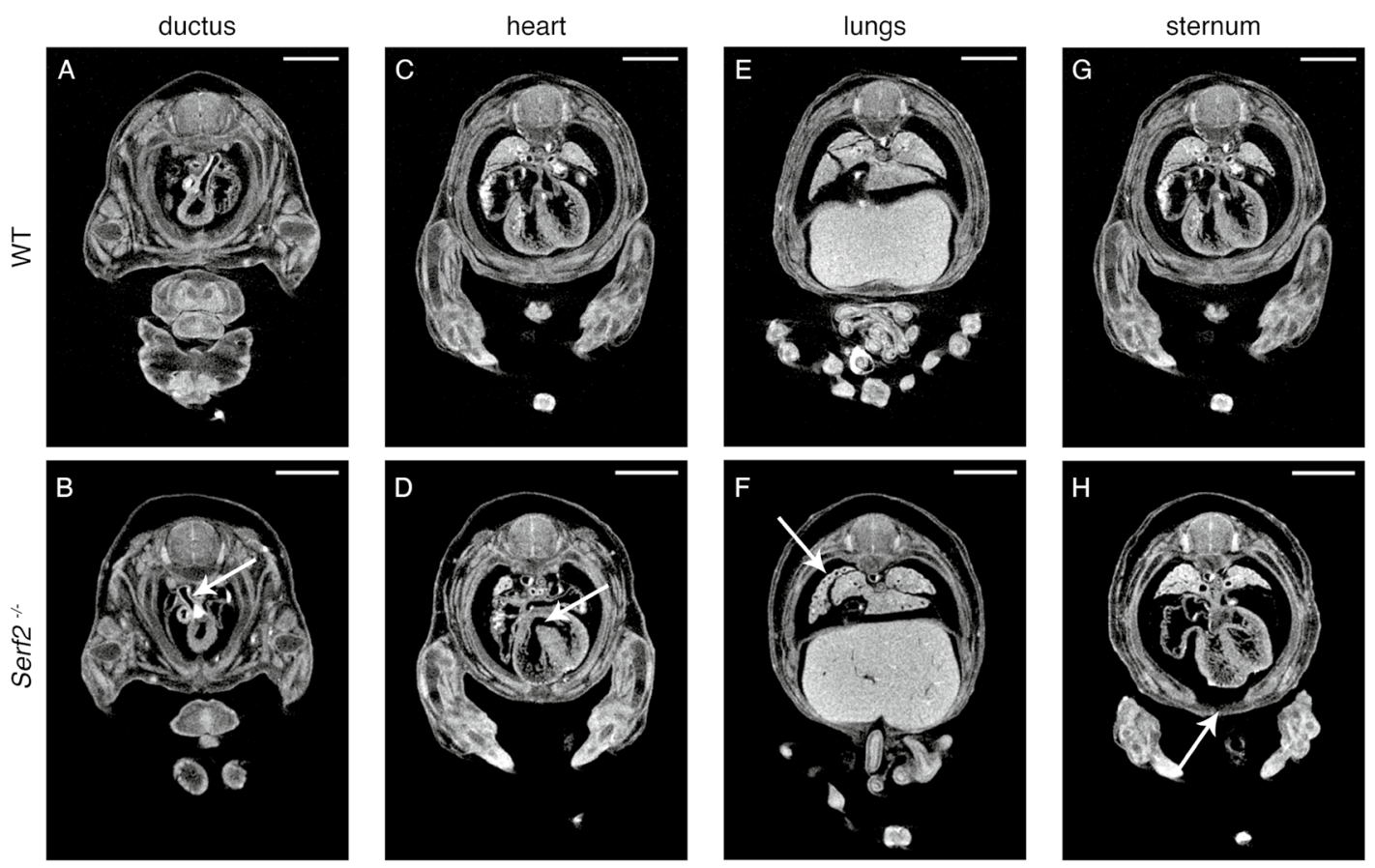

Fig. 2 Serf2 null knockout mice have developmental defects at E14.5 and are embryonic lethal on a C57BL6/Ntac background. a Table showing genotypes of E12.5, E14.5, E18.5-day embryos produced by a heterozygous Serf $2^{+/-}$intercross on the C57BL/6NTac background. b Micro CT 3D assessment of E14.5 wildtype (WT) and homozygous

\section{Serf2 ${ }^{+/-}$heterozygous knockout male, but not female, mice have a deficit in startle response and pre-pulse inhibition}

Adult heterozygous $\operatorname{Serf2}$ knockout mice ( $\operatorname{Serf} 2^{\text {tmlb }}$ allele) on the C57BL/6NTac background were put through a pipeline of standardised tests used by the International Mouse Phenotyping Consortium (IMPC) (data not shown, available at https://www.mousephenotype.org/data/genes/MGI:13370 41).

At 10 weeks of age, $\operatorname{Serf} 2^{+/-}$male but not female mice had significantly increased response amplitudes in the acoustic startle test (Fig. 3a) and increased pre-pulse inhibition

Serf $2^{-/-}$embryos, white arrows indicate site of defect: A, B altered angle of entry of the pulmonary trunk ductus arteriosis, see white arrow in $\mathbf{B} ; \mathbf{C}, \mathbf{D}$ an interventricular septal defect, see white arrow in $\mathbf{D} ; \mathbf{E}, \mathbf{F}$ delay in lung lobe development; $\mathbf{G}, \mathbf{H}$ delay in rib fusion: sternum primordium, see white arrow in $\mathrm{H}$. Scale bar $=1 \mathrm{~mm}$

(Fig. 3b). No other significant differences from wildtype were detected in the standard testing data.

\section{Serf $^{-/-}$null animals on a mixed genetic background survive to adulthood}

When Serf2 $2^{+/-}\left(\operatorname{Serf} 2^{\text {tmld }}\right.$ allele) heterozygous breeders, made congenic by maintaining on a C57BL/6 J background for 6 generations were subsequently crossed over two generations to a mixed 129S8, C57BL/6/Nimr genetic background (Cohort B), homozygous null Serf $2^{-/-}$progeny were produced that survived to adulthood i.e. at least 3 months of age. The percentages of pup genotypes on this mixed 
(A)

(B)

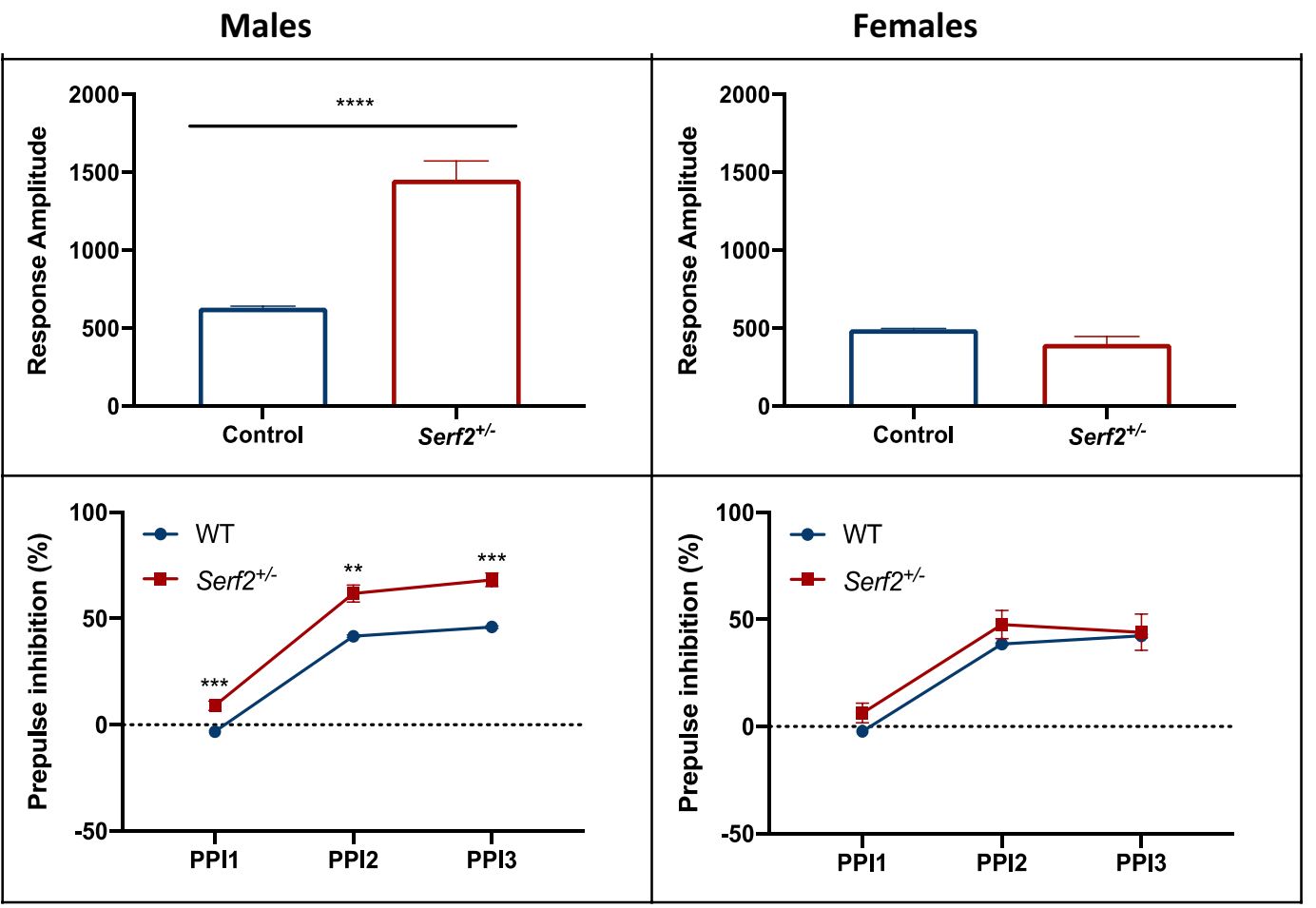

Fig. 3 Acoustic startle and pre-pulse inhibition tests on wildtype and Serf2 heterozygous knockout adults (C57BL/6NTac background). a Acoustic startle test. Acoustic startle testing was carried out with 1082 wildtype male, 1083 wildtype female, $8 \operatorname{Serf}^{+/-}$males, and 7 $\mathrm{Serf}^{+/-}$females at 10 weeks of age. Animals were habituated to the chamber with a background noise of $53 \mathrm{~dB}$ for $5 \mathrm{~min}$. ASR without pre-pulse. Serf $2^{+/-}$male mice exhibited significantly greater startle responses compared to WT mice (Mann-Whitney; Males: $\mathrm{p}<0.0001$, $U=367$; Females: $p=0.2215, U=2774)$. b Pre-pulse inhibition test. Pre-pulse inhibition (PPI) tests were carried out with 1082 wildtype male, 1083 wildtype female, $8 \operatorname{Serf}^{+/-}$male, and $7 \operatorname{Serf}^{+/-}$female

background were $15 \%$ wildtype, $65 \%$ heterozygous and $19 \%$ homozygous null littermates, indicating no significant loss of null animals (Chi Square test, $\mathrm{p}=0.1$ ). Note that these data are on the $\operatorname{Serf} 2^{\text {tmld }}$ allele, not the $\operatorname{Serf2^{\text {tmlb}}}$ allele as used above.

Serf2 expression analysis on this hybrid background was performed by quantitative RT-PCR (qRT-PCR) on cortical homogenates from Serf $2^{-/-}$knockout, heterozygous $\operatorname{Serf}^{+/-}$and wildtype littermates at 3 months of age (Fig. 4a). Analysis showed that total expression of all $\operatorname{Serf} 2$ isoforms was reduced by $50 \%$ in the heterozygous $\operatorname{Serf} 2^{+/-}$mice and was undetectable in the Serf $2^{-/-}$knockout mice, compared to expression levels in wildtype littermates. Loss of the $7 \mathrm{kDa}$ SERF2 protein was confirmed by western blot analysis of cortical homogenates from null mice using wildtype littermates as controls (Fig. 4b).

Both the $\operatorname{Serf}^{-/-}$null and heterozygous $\operatorname{Serf2^{+/-}}$ animals (Serf2 ${ }^{\text {tmld }}$ allele) on the hybrid background, males and females, displayed general good health and lived beyond 3 mice at 10 weeks. Animals were habituated to the chamber with a background noise of $53 \mathrm{~dB}$ for $5 \mathrm{~min}$. PPI at three different pre-pulse intensities $(56,58,65 \mathrm{~dB})$. PPI values were measured after the startle tone $(120 \mathrm{~dB})$, following a pre-pulse and an $80 \mathrm{~ms}$ gap at background noise. Ninety trials were performed in pseudorandom order, with the interstimulus interval varying from $20-30 \mathrm{~s}$. Serf $2^{+/-}$male mice displayed significantly more PPI than wildtype mice at PPI1, PPI2, and PPI3 (unpaired t-test with Welch's correction; PPI1: $\mathrm{p}=0.0007$, $\mathrm{t}=5.323, \mathrm{df}=8.017 ;$ PPI2: $\mathrm{p}=0.0014, \mathrm{t}=4.967, \mathrm{df}=7.303$; PPI3: $\mathrm{p}=0.0002, \mathrm{t}=6.863, \mathrm{df}=7.410)$

months of age. There were no obvious differences between wildtypes, heterozygotes and homozygotes of both sexes. Phenotyping was not performed on these mice.

\section{Discussion}

The SERF2 protein is highly conserved and has already been shown to play a role in protein binding and aggregation formation in C. elegans (van Ham et al. 2010) and $S$. cerevisiae models (Meinen et al. 2019), as well as human cell lines (Balasubramaniam et al. 2018). Our interest in this protein arose from our research into different forms of neurodegeneration and the need for an in vivo model to investigate the potential physiological and pathological roles of SERF2 in a whole mammalian organism. In this study we bred heterozygous and homozygous knockout animals on different genetic backgrounds in order to conduct standardised phenotyping using the IMPC pipeline. Our results 


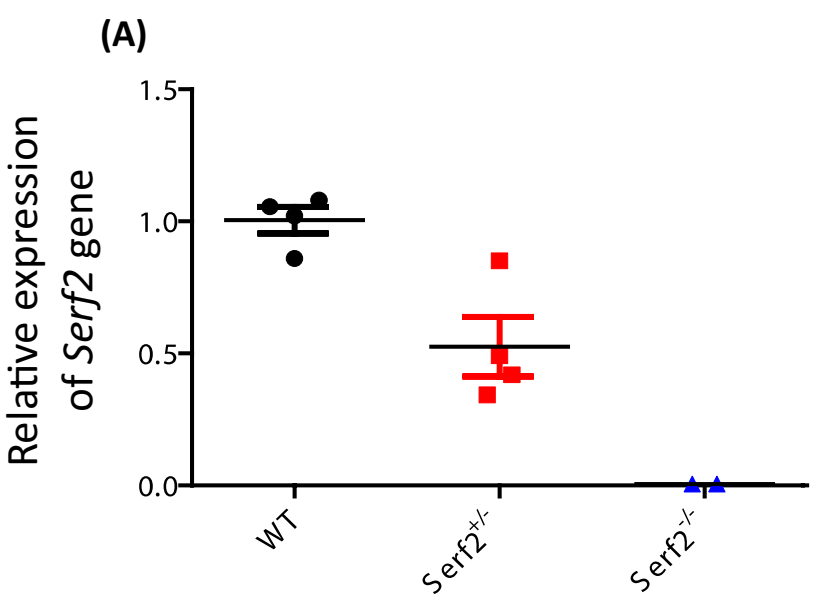

(B)

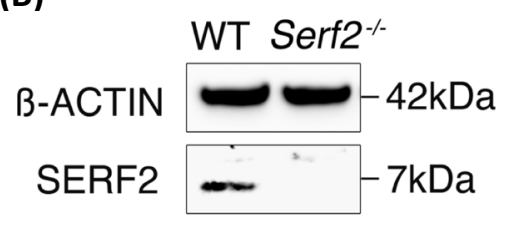

Fig. 4 Serf2 null mice are viable and do not express SERF2 on the mixed genetic background a Q-RT-PCR of cortex from 3-month-old wildtype, heterozygous and homozygous littermates shows no detectable expression of Serf2 from the targeted null allele, Serf ${ }^{\text {tmll }}$ (black circles wildtype, red squares heterozygous, blue triangles homozygous littermates). b The $7 \mathrm{kDa}$ SERF2 protein is not detectable in cortex of 3-month-old null animals

show a modulating effect on SERF2 loss by unknown genes in the mouse genome, although we note the Serf $2^{\text {tmld }}$ allele survived on the mixed background rather than the $\operatorname{Serf} 2^{\text {tmll }}$ allele which was used on the inbred C57BL/6 $\mathrm{N}$ background; an effect of the individual knockout allele on embryonic lethality seems unlikely but could be investigated further in new mouse crosses. The knockout alleles indicate a role for SERF2 in the nervous system with significant behavioural and neurological deficits in mice with knockout alleles (Fig. 3), and also a wider role for this protein in development (Fig. 2) and in the adult (Fig. 1).

On the C57BL/6 N background Serf2 heterozygous animals survived to adulthood but the null animals did not survive beyond P1 (Fig. 2, Table S2A). MicroCT imaging indicated developmental delay in homozygous null animals but this appeared to largely resolve towards term. Nevertheless, no live null mice were born on this genetic background.

Through analysing the LacZ expression pattern of the $\operatorname{Serf}^{+/-}$mouse with the tm1b allele (C57BL/6 N), we found expression was not ubiquitous and in part had a sex-specific pattern with expression in some male tissues but not the female equivalent (Fig. 1, Supplementary Table S1). At the transcript level, we note the widespread SERF2 mRNA expression in the mouse and human nervous system, and in endothelial cells (www.brainrnaseq.org).

In heterozygous mice on the C57BL/6 $\mathrm{N}$ background we found deficits in acoustic startle response and in prepulse inhibition in adult males, not females, indicating some form of neuronal deficit in these animals (Fig. 3). The startle amplitude is higher in males than females (which are comparable to wildtype littermates) i.e. males jump further in response to the tone. The apparently increased pre-pulse inhibition may in part arise from the increased startle, but this response should be investigated further.

The male-specificity of gene expression in a few tissues and these behavioural phenotypes was an unexpected result from this autosomal gene, which should be investigated further in a larger cohort of mice.

On the mixed genetic background, we found homozygous null animals were produced at Mendelian ratios. We saw no obvious deficits in these mice, but it would be interesting to look using the standardised IMPC phenotyping pipeline and to behaviourally test these mice in depth, which we did not do.

Although SERF1 and SERF2 proteins share structural homology and have a similar biological function in vitro, interestingly the Serfl knockout mouse presents quite different phenotypes from the Serf 2 knockout mouse. These include increased circulating cholesterol levels and decreased bone mineral density in females, and increased heart weight in males (data available at https://www.mouse phenotype.org/data/genes/MGI:1337114). These data suggest that, in vivo, SERF1 may have a role in cellular protein homeostasis.

Although we do not have expression data available for Serf1, qualitative Serf2 adult expression data for the C57BL/6 N genetic background can be found at:

https://www.mousephenotype.org/data/genes/MGI:13370 41\#phenotypesTab

The Serf2 locus is located on mouse chromosome 2, which has homology to human chromosome 15q15.3. Several schizophrenia susceptibility loci have been identified on chromosome 15 (Tsuang et al. 2001; Stephens et al. 2012; Wang, Liu, and Aragam 2010), including an auditory-evoked response inhibition phenotype associated with region 15q14 (Freedman et al. 1997). In addition, there is evidence for genetic linkage of chromosome 15 and bipolar disorder (Turecki et al. 2001; Vazza et al. 2007). A human deafness-infertility syndrome has also been mapped to this region, although likely due to a deletion $\sim 100 \mathrm{~kb}$ away (Zhang et al. 2007). Intriguingly we find male-specific behavioural and neuronal phenotypes in our mice, given the evidence supporting the contribution of multiple 15q genes to schizophrenia (Stephens et al. 2012), this could be of significance. Interestingly the $S E R F 2$ gene in both human and mouse is adjacent to, and 
in the same orientation as, huntingtin interacting protein $\mathrm{K}$ (HYPK). HYPK can act as a chaperone to suppress mutant huntingtin aggregates (Raychaudhuri et al. 2008). Connected via a conjoined gene these two genes are regulated by a common transcription factor yet their protein products have opposite cellular functions in regulating protein aggregation (Das and Bhattacharyya 2016).

Given the known role of SERF proteins in modulating aggregation, these Serf2 $\mathrm{KO}$ mice provide an in vivo platform to investigate the role of SERF2 protein in the pathology of neurodegenerative diseases. Crossing the mice to mouse models of neurodegeneration will provide new insights into disease-related protein aggregation and potentially advance the identification of new therapeutic targets. Finally, all Serf2 knockout alleles described here, and the conditional allele $\operatorname{Serf} 2^{\text {tmlc }}$, are freely available via the International Mouse Knockout Project at https://www. mousephenotype.org

Supplementary Information The online version contains supplementary material available at https://doi.org/10.1007/s00335-021-09864-6.

Acknowledgements We thank the MRC Prion Unit Biological Services Facility at UCL for the essential management, maintenance and husbandry of mice.

Authors' contributions CK: Analysis, Investigation, Writing-Original Draft Preparation, Writing-Review and Editing; CT: Analysis, Investigation; LWC: Analysis, Figure design; RM: Analysis, Investigation; CTJ: Conceptualisation; CJ: Analysis, Investigation; MJ: Analysis, Investigation; SZ: Analysis, Investigation; SM: Analysis, Investigation; TL: Analysis, Investigation; MP: Analysis, Investigation; MC: Conceptualisation; WS: Conceptualisation; WFK: Conceptualisation, Funding Acquisition, Writing-Review and Editing; FEMC: Conceptualisation, Funding Acquisition, Writing-Review and Editing.

Funding The authors were funded by a Wellcome Trust Strategic Award (Grant Number: 098330/Z/12/Z) awarded to The London Down Syndrome (LonDownS) Consortium (E.M.C.F). Additionally, the authors are funded by a Wellcome Trust Joint Senior Investigators Award (E.M.C.F.), the Medical Research Council (Programme Grant G0601056 awarded E.M.C.F), as well as by awards from Alzheimer's Research UK (awarded to F.K.W and E.M.C.F), Alzheimer's Society (awarded to E.M.C.F and F.K.W.), Epilepsy Research UK (awarded to F.K.W.) and The Collaborative Center for X-linked Dystonia Parkinsonism (awarded to W.C.L.). The generation and initial phenotyping of the mice was part of the International Mouse Phenotyping Consortium and supported by the Mary Lyon Centre, funded by Medical Research Council (Grant A410). F.K.W. is supported by the UK Dementia Research Institute which receives its funding from DRI Ltd, funded by the UK Medical Research Council, Alzheimer's Society and Alzheimer's Research UK and also holds an Alzheimer's Research UK Senior Research Fellowship (ARUK-SRF2018A-001).The funders had no role in study design, data collection and analysis, decision to publish, or preparation of the manuscript.

Data availability All phenotyping data as mentioned in the text is available through the International Mouse Phenotyping Consortium (IMPC) website www.mousephenotype.org). As stated, all Serf2 knockout mice mentioned in the text are available through IMPC.

\section{Declarations}

Conflict of interest No competing interests were disclosed.

Ethical approval All animal studies were lisensed by the Home Office under the Animals (Scientific Procedures) Act 1986 Amendment Regulations 2012 (SI 4 2012/3039), UK, and additionally approved by the both Institutional Ethical Review Committees.

Open Access This article is licensed under a Creative Commons Attribution 4.0 International License, which permits use, sharing, adaptation, distribution and reproduction in any medium or format, as long as you give appropriate credit to the original author(s) and the source, provide a link to the Creative Commons licence, and indicate if changes were made. The images or other third party material in this article are included in the article's Creative Commons licence, unless indicated otherwise in a credit line to the material. If material is not included in the article's Creative Commons licence and your intended use is not permitted by statutory regulation or exceeds the permitted use, you will need to obtain permission directly from the copyright holder. To view a copy of this licence, visit http://creativecommons.org/licenses/by/4.0/.

\section{References}

Ayyadevara S, Balasubramaniam M, Gao Y, Yu LR, Alla R, Shmookler Reis R (2015) Proteins in aggregates functionally impact multiple neurodegenerative disease models by forming proteasome-blocking complexes. Aging Cell 14:35-48

Balasubramaniam M, Ayyadevara S, Reis RJS (2018) Structural insights into pro-aggregation effects of C. elegans CRAM-1 and its human ortholog SERF2. Sci Rep. https://doi.org/10.1038/ s41598-018-33143-1

Birling, Marie-Christine, Atsushi Yoshiki, David J Adams, Shinya Ayabe, Arthur L Beaudet, Joanna Bottomley, Allan Bradley, Steve DM Brown, Antje Bürger, Wendy Bushell, Francesco Chiani, HsianJean Genie Chin, Skevoulla Christou, Gemma F Codner, Francesco J DeMayo, Mary E Dickinson, Brendan Doe, Leah Rae Donahue, Martin D Fray, Alessia Gambadoro, Xiang Gao, Marina Gertsenstein, Alba Gomez-Segura, Leslie O Goodwin, Jason D Heaney, Yann Hérault, Martin Hrabe de Angelis, Si-Tse Jiang, Monica J Justice, Petr Kasparek, Ruairidh E King, Ralf Kühn, Ho Lee, Young Jae Lee, Zhiwei Liu, K C Kent Lloyd, Isabel Lorenzo, A. M. Mallon, Colin McKerlie, Terrence F Meehan, Stuart Newman, Lauryl MJ Nutter, Goo Taeg Oh, Guillaume Pavlovic, Ramiro Ramirez-Solis, Barry Rosen, Edward J Ryder, Luis A Santos, Joel Schick, John R Seavitt, Radislav Sedlacek, Claudia Seisenberger, Je Kyung Seong, William C Skarnes, Tania Sorg, Karen P Steel, Masaru Tamura, Glauco P Tocchini-Valentini, Chi-Kuang Leo Wang, Hannah Wardle-Jones, Marie Wattenhofer-Donzé, Sara Wells, Brandon J Willis, Joshua A Wood, Wolfgang Wurst, Ying Xu, IMPC Consortium, Lydia Teboul, and S. A. Murray. 2020. 'A resource of targeted mutant mouse lines for 5,061 genes', Nature Genetics.

Brown JM, Horner NR, Lawson TN, Fiegel T, Greenaway S, Morgan H, Ring N, Santos L, Sneddon D, Teboul L, Vibert J, Yaikhom G, Westerberg H, Mallon AM (2018) A bioimage informatics platform for high-throughput embryo phenotyping. Brief Bioinform 19:41-51

Chiti F, Dobson CM (2006) Protein misfolding, functional amyloid, and human disease. Annu Rev Biochem 75:333-366

Das S, Bhattacharyya NP (2016) Trans-activation of small EDRK-rich factor 2 (SERF2) promoter by Heat Shock Factor 1. Biochem Biophys Rep 7:188-194 
Dickinson ME, Flenniken AM, Ji X, Teboul L, Wong MD, White JK, Meehan TF, Weninger WJ, Westerberg H, Adissu H, Baker CN, Bower L, Brown JM, Caddle LB, Chiani F, Clary D, Cleak J, Daly MJ, Denegre JM, Doe B, Dolan ME, Edie SM, Fuchs H, GailusDurner V, Galli A, Gambadoro A, Gallegos J, Guo S, Horner NR, Hsu CW, Johnson SJ, Kalaga S, Keith LC, Lanoue L, Lawson TN, Lek M, Mark M, Marschall S, Mason J, McElwee ML, Newbigging S, Nutter LM, Peterson KA, Ramirez-Solis R, Rowland DJ, Ryder E, Samocha KE, Seavitt JR, Selloum M, Szoke-Kovacs Z, Tamura M, Trainor AG, Tudose I, Wakana S, Warren J, Wendling $\mathrm{O}$, West DB, Wong L, Yoshiki A, Consortium International Mouse Phenotyping, Laboratory Jackson, Institut Clinique de la Souris Infrastructure Nationale Phenomin, Laboratories Charles River, M. R. C. Harwell, Phenogenomics Toronto Centre for, Institute Wellcome Trust Sanger, Riken BioResource Center, MacArthur DG, Tocchini-Valentini GP, Gao X, Flicek P, Bradley A, Skarnes WC, Justice MJ, Parkinson HE, Moore M, Wells S, Braun RE, Svenson KL, de Angelis MH, Herault Y, Mohun T, Mallon AM, Henkelman RM, Brown SD, Adams DJ, Lloyd KC, McKerlie C, Beaudet AL, Bucan M, Murray SA (2016) High-throughput discovery of novel developmental phenotypes. Nature 537:508-514

Falsone SF, Meyer NH, Schrank E, Leitinger G, Pham CL, FoderoTavoletti MT, Holmberg M, Dulle M, Scicluna B, Gesslbauer B, Ruckert HM, Wagner GE, Merle DA, Nollen EA, Kungl AJ, Hill AF, Cappai R, Zangger K (2012) SERF protein is a direct modifier of amyloid fiber assembly. Cell Rep 2:358-371

Feldkamp LA, Davis LC, Kress JW (1984) Practical cone-beam algorithm. J Opt Soc Am 1:612-619

Freedman R, Coon H, Myles-Worsley M, Orr-Urtreger A, Olincy A, Davis A, Polymeropoulos M, Holik J, Hopkins J, Hoff M, Rosenthal J, Waldo MC, Reimherr F, Wender P, Yaw J, Young DA, Breese CR, Adams C, Patterson D, Adler LE, Kruglyak L, Leonard S, Byerley W (1997) Linkage of a neurophysiological deficit in schizophrenia to a chromosome 15 locus. Proc Natl Acad Sci U S A 94:587-592

Goedert M, Spillantini MG (2006) A century of Alzheimer's disease. Science 314:777-781

Hartl FU, Hayer-Hartl M (2009) Converging concepts of protein folding in vitro and in vivo. Nat Struct Mol Biol 16:574-581

Lansbury PT, Lashuel HA (2006) A century-old debate on protein aggregation and neurodegeneration enters the clinic. Nature 443:774-779

Meinen BA, Gadkari VV, Stull F, Ruotolo BT, Bardwell JCA (2019) SERF engages in a fuzzy complex that accelerates primary nucleation of amyloid proteins. Proc Natl Acad Sci U S A 116:23040-23049

Merle DA, Witternigg A, Tam-Amersdorfer C, Hartlmuller C, Spreitzer E, Schrank E, Wagner-Lichtenegger S, Werzer O, Zangger K, Kungl AJ, Madl T, Meyer NH, Falsone SF (2019) Increased Aggregation Tendency of Alpha-Synuclein in a Fully Disordered Protein Complex. J Mol Biol 431:2581-2598

Meyer NH, Dellago H, Tam-Amersdorfer C, Merle DA, Parlato R, Gesslbauer B, Almer J, Gschwandtner M, Leon A, Franzmann TM, Grillari J, Kungl AJ, Zangger K, Falsone SF (2020) Structural Fuzziness of the RNA-Organizing Protein SERF Determines a Toxic Gain-of-interaction. J Mol Biol 432:930-951

Ogen-Shtern N, Ben David T, Lederkremer GZ (2016) Protein aggregation and ER stress. Brain Res 1648:658-666

Raychaudhuri S, Sinha M, Mukhopadhyay D, Bhattacharyya NP (2008) HYPK, a Huntingtin interacting protein, reduces aggregates and apoptosis induced by $\mathrm{N}$-terminal Huntingtin with 40 glutamines in Neuro2a cells and exhibits chaperone-like activity. Hum Mol Genet 17:240-255

Scherzinger E, Sittler A, Schweiger K, Heiser V, Lurz R, Hasenbank R, Bates GP, Lehrach H, Wanker EE (1999) Self-assembly of polyglutamine-containing huntingtin fragments into amyloid-like fibrils: implications for Huntington's disease pathology. Proc Natl Acad Sci U S A 96:4604-4609

Skarnes WC, Rosen B, West AP, Koutsourakis M, Bushell W, Iyer V, Mujica AO, Thomas M, Harrow J, Cox T, Jackson D, Severin J, Biggs P, Fu J, Nefedov M, de Jong PJ, Stewart AF, Bradley A (2011) A conditional knockout resource for the genome-wide study of mouse gene function. Nature 474:337-342

Stephens SH, Franks A, Berger R, Palionyte M, Fingerlin TE, Wagner B, Logel J, Olincy A, Ross RG, Freedman R, Leonard S (2012) Multiple genes in the 15q13-q14 chromosomal region are associated with schizophrenia. Psychiatr Genet 22:1-14

Stroo E, Koopman M, Nollen EA, Mata-Cabana A (2017) Cellular Regulation of Amyloid Formation in Aging and Disease. Front Neurosci 11:64

Truett GE, Heeger P, Mynatt RL, Truett AA, Walker JA, Warman ML (2000) Preparation of PCR-quality mouse genomic DNA with hot sodium hydroxide and tris (HotSHOT). Biotechniques 29(52):54

Tsuang DW, Skol AD, Faraone SV, Bingham S, Young KA, Prabhudesai S, Haverstock SL, Mena F, Menon AS, Bisset D, Pepple J, Sauter F, Baldwin C, Weiss D, Collins J, Boehnke M, Schellenberg GD, Tsuang MT, Study Veterans Affairs Cooperative (2001) Examination of genetic linkage of chromosome 15 to schizophrenia in a large Veterans Affairs Cooperative Study sample. Am J Med Genet 105:662-668

Turecki G, Grof P, Grof E, D’Souza V, Lebuis L, Marineau C, Cavazzoni P, Duffy A, Betard C, Zvolsky P, Robertson C, Brewer C, Hudson TJ, Rouleau GA, Alda M (2001) Mapping susceptibility genes for bipolar disorder: a pharmacogenetic approach based on excellent response to lithium. Mol Psychiatry 6:570-578

van Ham TJ, Holmberg MA, van der Goot AT, Teuling E, GarciaArencibia M, Kim HE, Du D, Thijssen KL, Wiersma M, Burggraaff R, van Bergeijk P, van Rheenen J, Jerre van Veluw G, Hofstra RM, Rubinsztein DC, Nollen EA (2010) Identification of MOAG-4/SERF as a regulator of age-related proteotoxicity. Cell 142:601-612

Vazza G, Bertolin C, Scudellaro E, Vettori A, Boaretto F, Rampinelli S, De Sanctis G, Perini G, Peruzzi P, Mostacciuolo ML (2007) Genome-wide scan supports the existence of a susceptibility locus for schizophrenia and bipolar disorder on chromosome $15 \mathrm{q} 26$. Mol Psychiatry 12:87-93

Wang KS, Liu XF, Aragam N (2010) A genome-wide meta-analysis identifies novel loci associated with schizophrenia and bipolar disorder. Schizophr Res 124:192-199

Wiseman FK, Pulford LJ, Barkus C, Liao F, Portelius E, Webb R, Chavez-Gutierrez L, Cleverley K, Noy S, Sheppard O, Collins T, Powell C, Sarell CJ, Rickman M, Choong X, Tosh JL, Siganporia C, Whittaker HT, Stewart F, Szaruga M, Consortium London Down syndrome, Murphy MP, Blennow K, de Strooper B, Zetterberg H, Bannerman D, Holtzman DM, Tybulewicz VLJ, Fisher EMC, S Consortium LonDown (2018) Trisomy of human chromosome 21 enhances amyloid-beta deposition independently of an extra copy of APP. Brain 141:2457-2474

Yoshimura Y, Holmberg MA, Kukic P, Andersen CB, Mata-Cabana A, Falsone SF, Vendruscolo M, Nollen EAA, Mulder FAA (2017) MOAG-4 promotes the aggregation of alpha-synuclein by competing with self-protective electrostatic interactions. J Biol Chem 292:8269-8278

Zhang Y, Malekpour M, Al-Madani N, Kahrizi K, Zanganeh M, Lohr NJ, Mohseni M, Mojahedi F, Daneshi A, Najmabadi H, Smith RJ (2007) Sensorineural deafness and male infertility: a contiguous gene deletion syndrome. J Med Genet 44:233-240

Publisher's Note Springer Nature remains neutral with regard to jurisdictional claims in published maps and institutional affiliations. 